\title{
WARHOL Y SU DIMENSIÓN PUBLICITARIA HASTA LA ACTUALIDAD
}

\section{WARHOL AND ITS ADVERTISING DIMENSION TO THE PRESENT}

\author{
Enrique Mena García \\ Universidad Católica de Murcia
}

\section{RESUMEN}

Se pretende con la figura de Andy Warhol demostrar cómo trasciende todo lo originado en postulados artísticos y de diseño desde esos comienzos de la década de 1960, marcada por una nueva era de revolución social y contracultura. Situados en un contexto artístico de revulsivo expresionismo abstracto que camina en decadencia para dar paso al Arte Pop, con esa tendencia Kitsch que analizaremos, en especial en Warhol, cuyo prestigio perdura con una estética imperecedera. El método del artículo sigue los pasos de este icono artístico como poseedor de una doble cara, que acometió un giro trascendental en su carrera que lo catapultó hacia la fama al establecerse en Nueva York. Una popularidad evidenciada en su corriente artística que inunda el mundo de la publicidad y el marketing y, cuyo resultado sorprende en el momento de su aparición, como inflexión histórico-artística sin precedentes, que continua hasta la actualidad, en cuya discusión observamos como las tendencias perviven vigentes entre diseñadores, artistas y publicistas.

Palabras Clave: Andy Warhol, Publicidad, Arte Pop, Kitsch, Marketing

\begin{abstract}
It is intended with the figure of Andy Warhol to demonstrate how everything originated in artistic and design postulates has transcended since those early 1960s, marked by a new era of social revolution and counterculture. Set in an artistic context of revulsive abstract expressionism that is in decline, to give way to Pop Art, with that Kitsch trend that we will analyze, especially in Warhol, whose prestige endures with an imperishable aesthetic. The method of the article follows in the footsteps of this artistic icon as a possessor of a double face, who undertook a momentous turn in his career that catapulted him to fame when he settled in New York. A popularity evidenced in its artistic trend that floods the world of advertising and marketing and, whose result surprises at the time of its appearance, as an unprecedented historical-artistic inflection, which continues to this day, in whose discussion we observe how the trends they survive in force among designers, artists and publicists.
\end{abstract}

Key words: Andy Warhol, Advertising, Pop Art, Kitsch, Marketing 


\section{INTRODUCCIÓN}

Warhol es una leyenda ambigua a la que le gustaba ser sustituido por dobles, por el que, incluso, se duda de su nacimiento, que nunca dejó claro, y cuyo nombre artístico por el que es conocido se gestó a su llegada a Nueva York en 1949 (Honnef, 2005: 7). Su personalidad fue igual de creativa que su arte y supo entender a la perfección la simbiosis de arte y negocio.

Alicia Fernández (1999) escribió con motivo de la exposición del Guggenheim de Bilbao entre el 18 de octubre al 16 de enero del año 2000, que conoció "como pocos de las estrategias de mercado y promoción (...) Creó un nuevo tipo de artista relacionado directamente con la sociedad, fascinado por su siglo y en especial, por la cultura americana". Así pues, dio paso a un perfil artístico diferente hasta la fecha.

Sus cimientos comienzan cuando en sus vacaciones de verano trabaja en unos grandes almacenes, y se empapa del ambiente de consumo y publicidad que le ofrece una amplia visión. Su aureola aparenta frivolidad y algo de "dumb blond", como su modelo Marilyn Monroe, pero, son todo lo contrario, convertidos en estrellas y en la personificación del éxito americano.

En su trayectoria reside el estado de la cuestión, cuya continuidad de su indiscutible sello es una hipótesis que queremos confirmar, más potente después de su fallecimiento prematuro. Por consiguiente, establecemos un fenómeno "warholiano" en decoración, estética y diseño que no cesan.

El objetivo de la investigación, con la base historiográfica por la que se han escrito numerosos artículos científicos, es de tratar de demostrar cómo se reoriente y reinventa su mundo Pop hasta la actualidad, en un procedimiento artístico que a priori resulta sencillo, como muchos piensan, pero decisivo en la industria de las artes desde la segunda mitad del siglo XX hasta nuestra actualidad del siglo XXI.

\section{IRRUPCIÓN DE NUEVOS AIRES ARTÍSTICOS (LA SITUACIÓN)}

En la década de 1960 existe una vorágine de corrientes artísticas, con el minimalismo, los environments y los happenings. También el Pop Art se consolida, en un contexto de necesidad de cambiar al terreno de la figuración, después de la fuerza de la abstracción a partir de 1945 o Segunda Guerra Mundial, fecha habitual para comenzar con esta nueva era contemporánea que dejaba atrás a las vanguardias históricas. Díaz Gutiérrez (2010: 11) indica que, "el Pop Art recoge las imágenes publicitarias y las descontextualiza como crítica ante la publicidad, el arma más poderosa del consumismo. Parece ser que el idilio de la publicidad con el arte, o viceversa, se ha roto, pero es todo lo contrario".

Vinculados a este movimiento tenemos a precursores como Rauschenberg, Jasper Johns, Tom Wesselmann, Larry Rivers, etc., aunque, populares en el sentido de trascender en la cultura de masas son Lichtenstein, uno de los más imitados con sus acrílicos basados en tiras cómicas, junto con nuestro popular Andy Warhol, que experimentó además del terreno pictórico en cortometrajes y colaboró con cineastas como Paul Morrissey, gozando de una fama en vida.

Aunque, el origen real del Pop se sitúa en la capital británica, dada la fascinación por la nueva cultura popular urbana por la que se llevó a cabo una exposición llamada Esto es mañana en la galería de arte White Chapel de Londres, organizada por un grupo de artistas reunidos con el título de Independent Group en 1956 y con la que comenzaba su andadura, entre los que se incluían a los jóvenes Richard Hamilton, Eduardo Paolozzi, Henderson, William Turnbull, Alison y Peter Smithson, Peter Reyner Banham y Lawrence Alloway (Lucie-Smith, 1998: 128). Aunque, el movimiento inclinado a la "juventud, la moda, la cultura popular, el sexo y los medios de comunicación de masas" no se consagraría hasta la década siguiente (Gompertz, 2018: 323).

Así, situamos el nacimiento del Pop Art en Inglaterra, en contexto distinto al americano, que además de responder a preocupaciones sociales, hace crítica al arte más institucional (Fanés, 2000, 226). Llegó 1961 con la exposición de jóvenes artistas del Royal Collage of Art en los que figuraba David Hockney, obsesionados con las imágenes populares, alegría, insolencia, como en otro orden de cosas ocurría en la música de The Beatles, y otros aspectos 
socioculturales como el consumo de drogas, la forma de vestir, la sexualidad, revueltas estudiantiles, políticos soñadores asesinados, que derivaron a la denominada época de la contracultura y Swinging Sixties.

El movimiento Pop tuvo su cénit acompañado de un contexto general en Estados Unidos de nuevos hábitos de consumo, estabilidad política, económica y desarrollo de tecnologías que favorecían el confort en la clase social media (Bourlot, 2010: 93). La atracción hacia la cultura popular que sucedía en películas, publicidad, música, etc., de alguna manera sí era común en EE. UU.

Algunos de esos artistas tendrán como iconos los mitos románticos de la generación anterior que acabaron en una muerte trágica como los pintores Arshile Gorky y Jackson Pollock, o el actor James Dean, del que podemos extraer la importancia de una buena muerte, y que reproducirán a menudo alcanzando la inmortalidad (De Diego, 1999: 25).

Después, con unos años en cierto letargo, irrumpe con fuerza con la corriente neopop de los 80 y continua su estela e influjo en la actualidad, ya que, solo con clicar en un dispositivo digital cualquier tendencia asociada al Pop, irrumpe un extenso campo visual de marcas y publicidad diversa.

En esta cultura de consumo masivo, que es más despersonalizada y deshumanizada en Warhol, apuntamos con sus films, no tan célebres como su pintura, en ese cine marginal, como recrea un mundo underground, sugerente, experimental, nada convencional y casi o nada de narración, a modo de antropólogo de una ciudad, Nueva York (Minguet, citado en Fanés, 2000: 225), en una pasión por la ciudad y la muchedumbre (Spies, 1990: 27). Esta ciudad se convertirá en la ciudad exponente del Pop, camaleónica, cinematográfica y fascinante, donde afloran dos barrios culturales como Greenwich Village y el Soho en el distrito de Manhattan, acompañado del fenómeno contracultural con la generación beat, el movimiento hippie y el punk.

Época de carrera espacial entre la URSS y Estados Unidos que sería conocida como Guerra Fría, de nuevos conflictos en Oriente Medio, Cuba y Vietnam, acompañados de hitos en la igualdad de los derechos, con la corriente de pacifismo y protestas unidas a la rebelión estudiantil de 1968, con grandes festivales de música y una televisión que, prácticamente entra en casi todos los hogares de Norteamérica. Esto producirá una comunicación visual inmediata, cuya audiencia se multiplicaba en una sociedad más globalizada, a modo de "aldea global", término creado por el referente del periodismo y comunicación Marshall McLuhan.

En ese éxito rotundo en EE.UU., despertando un mayor nacionalismo, reflejo de la sociedad y en línea con el "sueño americano", recogemos como en algunos artistas como Claes Oldenburg existía una relación de elementos cotidianos gigantes entre escultura y pintura, que iban desde una hamburguesa hasta una batidora, signo de un sistema cultural en exponente desarrollo (Lucie-Smith, 1998: 156). Se presenta una atracción de lo prosaico, donde estos objetos humildes son susceptibles de transformarse en obras de arte (Rodríguez Pedret, 1991: 107).

\section{WARHOL, DE PUBLICITARIO A ARTISTA TOTAL}

Andy Warhol (1928-1987), es sin duda el más polémico y célebre de todos aquellos que forman el movimiento Pop, un gran ideólogo que no se quedó en las artes plásticas. De estudiar artes en el Instituto Carniege de Tecnología de Pittsburgh, finalizando en 1949, en una etapa marcada por la muerte de su padre cuando contaba tan solo 14 años (trabajador de las minas de carbón de West Virginia) (Honnef, 2005: 12), a la fama en escasos 14 años fulgurantes cuando creó su famoso taller The Factory en la calle $\mathrm{n}^{\circ} 47$ de Manhanttan (conocido como Silver Factory), cambiando a otras dos ubicaciones como la sexta planta del $\mathrm{n}^{\circ} 33$ de Union Square West y en el no 860 de Broadway (Pastor, 2016). Todo gracias al giro de marchar con su madre a Nueva York nada más acabar su formación académica y comenzar pronto como ilustrador en revistas como Vogue, Harper's, Bazaar, Seventeen, Tiffany, New Yorker, etc., aunque, ya no era Andrew Warhola, estaba naciendo un icono de masas.

Warhol era el hijo menor de emigrantes polacos católicos que tuvieron tres hijos, criado de forma humilde en un entorno conservador. Una vida de contrapuestos, con doble 
rostro por su pasado, de ahí la ambigüedad referenciada del inicio, como: frío y carismático, recatado y extravagante, tímido y pro cultura de masas, que quería destacar y tener éxito. Para lograrlo tuvo que reinventarse, pero, vivió en una farándula neoyorkina, entre la discoteca Studio 54, galerías de arte, la experimentación del cine y su condición sexual que nunca ocultó, exceptuando su calvicie a través de pelucas.

La oportunidad le vendría en una galería de arte en Los Ángeles en 1962, ya que por Nueva York no tuvo posibilidades, exponiendo su famosa Sopas Campbell. En ese mismo año vendería su primer retrato, Díptico de Marilyn con la introducción de la técnica de la serigrafía. Aprovechó sus vivencias con influencias neodadás como Johns y Rauschenberg, hasta la action painting y las viñetas de tebeos que leía de pequeño.

Warhol era un lobo, que aprovechaba cualquier oportunidad de engrandecerse, con cierto narcisismo y de turbulentas relaciones, como con Jean-Michel Basquiat, retroalimentándose ambos de sí mismos en esa relación compleja (Petit, 2019).

Sus retratos esconden a ídolos que ocultan mucho más, según Pinilla (2012: 56), los cuáles, tenían problemas de todo tipo: psicológicos, drogadicción, políticos e infidelidades, que desembocaron en tragedias, a excepción de Elizabeth Taylor, demostrando que no eran felices en esas fingidas sonrisas. Esos retratos de divos, muchos del espectáculo, los tenemos en Elvis Presley, Mick Jagger, Marilyn o Marlon Brandon, extraídos algunos de fotógrafos que los habían inmortalizado en sus películas, mientras él se dedicaba a jugar con los fondos. Continuó con personajes del coleccionismo o el star system europeo, conocidos como los vanity portraits, o los retratos de gobernadores de los años 70 presentados con ironía y potente colorido, y también de colegas de la cultura como Basquiat, Tennessee Williams, Joseph Beuys, Philip Johnson, Keith Haring, Man Ray, etc. Revitaliza este género en las décadas de 1970 y 1980. Fue calificado por el historiador del arte Robert Rosenblum (citado por Honnef, 2005: 89) como "el pintor de la corte de los años 70".

Hay que detenerse en el autorretrato, del que no dejó de realizar toda la vida, por el que apreciamos ya esa máscara que siempre llevará y que no dejará traspasar, que seguirá produciendo solo y desafiante a modo de ficha policial, con ese descaro que contrasta con su lado poco accesible, hasta alcanzar 1986 con un semblante intenso y demacrado como signo de su final, la mayor de las veces con grandes contrastes de colores yuxtapuestos. Sobre su mundo del color y transparencias, Warhol, quizá por su ascendencia eslava como apunta Fernández Campón (2006: 238) afronta las obras con una fijación en la luzy color que recuerdan a cierta estética medieval, de tradición cristiana. A veces, ese color será monócromo, como el fondo dorado de Gold Marilyn (1962), S\&H Green Stamps (1962) o Cuatro Jakies (1964), que Melero Guirado (2019: 4) llama "ausencias", que arrastra a pensar en cierto minimalismo, y que repetirá en secuencias con el fotomatón a modo de polípticos o con su cámara Kodak, con esos colores metalizados que recuerdan a las icónicas imágenes bizantinas. Son obras detenidas en el tiempo, en un instante permanente, que Spies (según Honnef, 2005: 66) afirma que son efecto de una angustia vital soterrada, desvalorizando la exclusividad debido a la repetición, "que corroe la imagen individual".

Recoge De Diego (1990: 116), que el juego de la mirada en Warhol es potentísimo y su escarceo perverso inaugura una estrategia que se populariza en los 80. Se trata de "travestir la mirada porque, liquidado el misterio, sólo quedaba lo asombroso". En los últimos años 60 se siente famoso y se representa apuntando hacia sus ídolos de Hollywood y su ambigüedad sexual (Truman Capote, Garbo, Marilyn, etc.), y al final de su trayectoria (años 70 y 80), más que trascender como estrella quiere pasar como un artista célebre al igual que los clásicos, por lo que jugará con las manos y la muerte con calaveras. Reflejo de una evolución de sus estados de ánimo, de su juego de esconderse y disfrazarse.

"Llegó al extremo de convertirse él mismo en una marca" (Gompertz, 2018: 340). Warhol nunca escondió su aspecto comercial y de fama, aplicando la serigrafía como impresión seriada. El nombre de su estudio The Factory lo decía todo, e incluso sin importar que fuera la obra hecha por él, porque solo era necesario su autentificación, y lograr el caché social, de inversión y prestigio de tener "un Warhol", independientemente de lo que fuera, ya que para muchos era una buena compra. Una Factory que congregó en la cadena de montaje a músicos, directores, actores, performers, etc., incluso, de personas más extravagantes que él, más gays 
que él, incluso marginales, quizás como método de defensa ante un país homofóbico (Junca, 2010). Esta Factory tiene cierto paralelismo con las "botteghe" del renacimiento por las que el maestro solo retocaba y culminaba procesos por las que pasaban oficiales y aprendices que cumplían unos patrones y reglas. Warhol se aleja de ese patrón del Pop de composición de imágenes de consumo, clichés, cómics, etc., según Spies (1990: 29), puesto que elabora una "sofisticación" de la imagen.

\section{1. ¿QUÉ LE DEBE LA PUBLICIDAD A WARHOL?}

Antes de dar respuesta, las primeras preguntas ante esta irrupción Pop en la publicidad serían: ¿Qué tiene Warhol que no tengan otros? y ¿Por qué esta estética es tan frecuente y perdura en marketing?. Gustase o no, los años 60 y 70 respiran Arte Pop, reaccionando lo popular ante la corriente anterior. Una evidencia del cambio de una alta cultura a una cultura de masas.

Los artistas de vanguardia del 1900 descubrieron con la unión del arte y la publicidad a través del cartel una alternativa creativa, donde el arte entraba en la publicidad, y con la era del Pop el fenómeno es inverso, donde la publicidad se introduce en el arte como parte esencial de la cultura postmoderna (Heredero y Chaves, 2016: 97). Para la mayor parte de la población, esas litografías cromáticas más asequibles y populistas salidas de su Factoría, se ajustaban a la demanda. La lata de tomate más famosa del mundo, Sopas Campbell, es una de las más vendidas de todo el mundo, una marca que ha transcendido, cuyo branding, esa estrategia de hacer y construir una marca, catapultó a cotas inimaginables en ese momento a su autor.

Warhol fue y sigue siendo el mítico e icónico gurú perpetuado hasta adoptar el título de "Papa del pop". Buscó iconos en el diseño con productos al alcance de todos como Coca Cola, la supremacía del derecho a ser libres con el dólar, o el orgullo de la nación con su bandera, cuyo germen se gesta con el capitalismo y el avance tecnológico, asegura Pinilla (2012: 60), donde el Pop seguirá siendo importante "demostrando que los ídolos y los símbolos de la sociedad pueden llegar a alterar nuestros sentimientos (...) referentes con los que siempre nos identificamos, bien sea de manera directa o actitudinal".

La obra de Warhol sigue muy vigente y actual. La prueba es la cantidad de exposiciones que se suceden, como la llevada a cabo en España en tres ciudades distintas desde el 14 de septiembre de 2017 al 16 de septiembre de 2018, titulada Warhol. El arte mecánico, primero por los CaixaForum de Barcelona y de Madrid, hasta llegar al Museo Picasso de Málaga. Fuera de España, se celebró recientemente en la Tate Modern de Londres desde el 12 de marzo y prorrogada hasta el 15 de noviembre 2020, una gran retrospectiva ${ }^{1}$.

La continuidad en artistas que recurren a esas actitudes del Pop, las tenemos en artistas como Julian Schnabel, teniendo presente la autopromoción, el reclamo publicitario, convertido en el artista más admirado, según Guasch (2000: 360), de la era Reagan, a modo de "monstruo del ego".

Junto al rebelde grafitero Jean-Michel Basquiat, otro artista con tendencia Pop y que bebió de los influjos de Warhol es Kenny Scharf creando un pop exótico y psicodélico con "figuras sacadas de los dibujos animados con personajes mitológicos, en una búsqueda de lo raro, curioso y divertido" (Guash, 2000: 376).

Existen muchos más continuadores con nuevas narrativas Pop, por lo que la estética persiste ejemplificado en artistas americanos como Paul Rousso ${ }^{2}$ y Mel Bochner ${ }^{3}$, o artistas más locales como el murciano Gaby Guillén ${ }^{4}$, en un estilo que él mismo denomina art-Pop mediterráneo (Botías, 2017).

Célebres en vida son los ingleses David Hockney, Allen Jones, Julian Opie, americanos como Raymond Pettibon, Edward Ruscha, Jeff Koons y Wayne Thiebaud, el alemán Hans Haacke, y los japoneses Yayoi Kusama, Takashi Murakami y Yoshitomo Nara. La escultura es otra de las grandes representantes de este arte Pop, cuyas figuras monumentales de Koons, recuerdan al pionero Claes Oldenburg en esas monumentales obras urbanas.

\footnotetext{
1 (Canal Web de la Tate Modern, http://bit.ly/2Lue86m. Enlace visitado el 09/01/2021).

(Canal Web de Paul Rousso: https://paulrousso.com/. Enlace Web visitado el 15/01/20221).

(Canal Web de Mel Bochner: http://www.melbochner.net/. Enlace Web visitado el 15/01/20221).

(Canal Facebook de Gaby Guillén: http://bit.ly/3aPqrDb. Enlace Web visitado el 15/01/20221).
} 


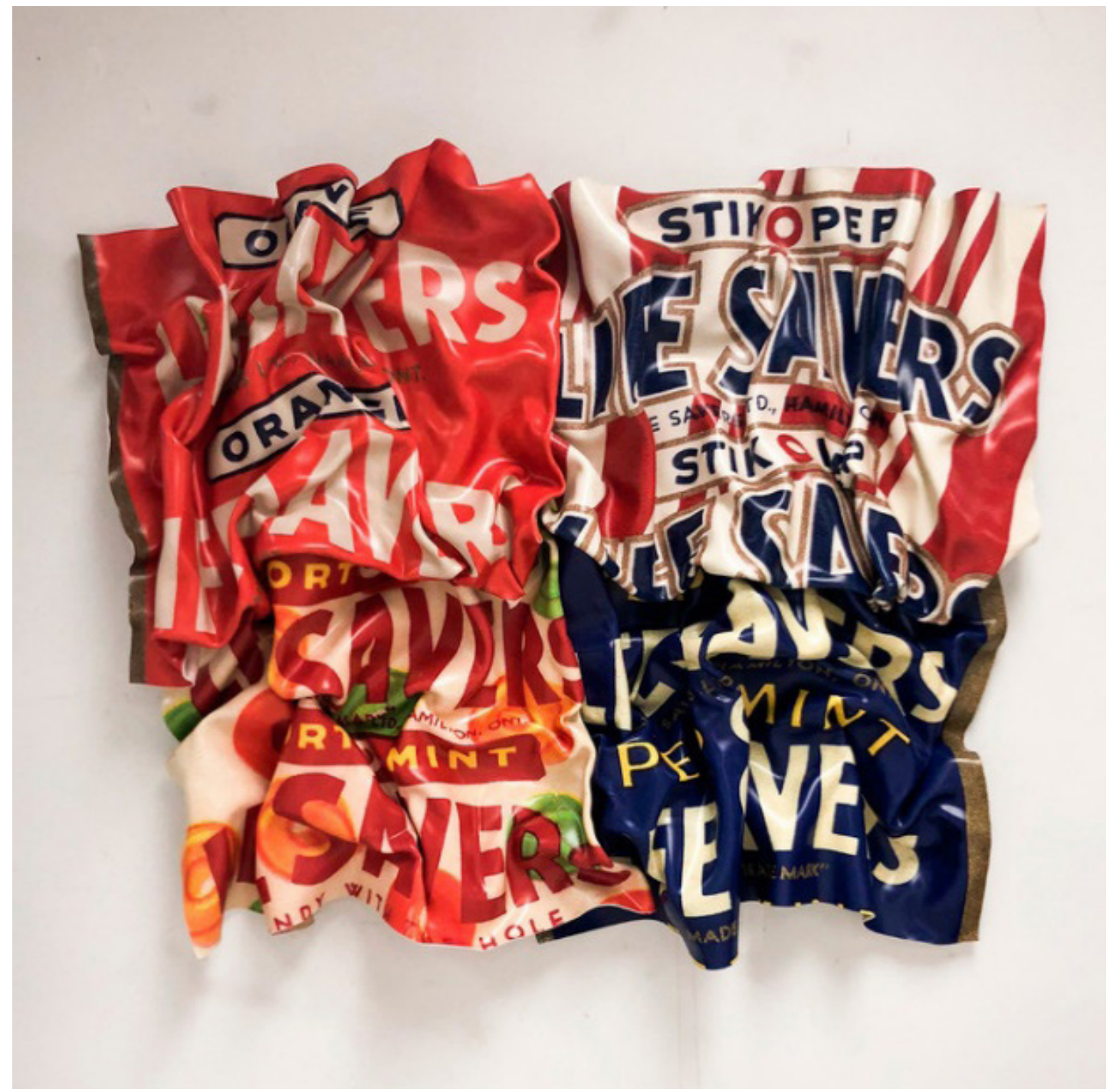

Figura 1. Paul Rosso. Four flavor crush. 2018. Técnica mixta ${ }^{5}$

Según Amezcua (2013: 20), los precursores ingleses tomaron la cultura de masas como inspiración, trasladándose a la arquitectura e interiores como la tienda BIBA en Londres que diseñó su propietaria Bárbara Hulanichi en 1964, punto de encuentro de mucha gente, organizando fiestas, y extensible a películas del momento como 2001, Una Odisea del espacio, en la que el diseñador de interiores francés Oliver Mourgue creó asientos futuristas bajos y de colores brillantes. Un interiorismo que perdura en infinidad de revistas y catálogos. Aunque, la influencia en el mobiliario y en edificios nunca ha sido tan notable como en la publicidad gráfica y audiovisual.

En nuestra era digital y desenfreno consumista, la estética Pop encaja muy bien, e Internet ofrece un escaparate a diseñadores o ilustradores que son atrapados por su magnetismo, como la ilustradora Be Fernández con un toque urbano y Pop que arrasa en Instagram ${ }^{6}$, una etiqueta Pop que no debe importar, porque lo que hacen es agrandar el estilo cono renovadas ideas. Sin duda, un ejemplo de tantos, que desde las Redes Sociales suben sus investigaciones y enriquecen el Pop con nuevas aportaciones. Con esto damos respuesta a la pregunta de inicio, cuya publicidad debe rendir pleitesía a este mago de la publicidad y el marketing. No solo por la estela que ha encadenado la publicidad, ya que, muchas creaciones en su etapa de esplendor Pop siguen tan vigentes y actuales como el primer día.

5 Imagen recuperada de https://bit.ly/3q0rFSo. Web visitada el 21/01/2021.

6 (Canal Web de Be Fernández: https://www.befernandez.com/. Enlace Web visitado el 12/01/2021) 


\section{LA DEBILIDAD DE LA PUBLICIDAD POR EL POP (RESULTADOS)}

El Pop Art o Arte Pop se ha convertido en un ejemplo del excelente maridaje del mundo del arte con el mundo de la publicidad. Es uno de los movimientos más recurridos en cuanto a marketing se refiere, recurso o herramienta de la publicidad inspirados en esta corriente artística.

El marco espacio-temporal abarca desde las primeras creaciones de Warhol hasta la actualidad, y la discusión de nuestra hipótesis comienza enlazando todo lo creado por este artista, cuya aparición marca un antes y un después en el arte publicitario. A raíz de 1987, con su fallecimiento, existe una inflexión en el mercado publicitario abrumadora, demostrada por la inmensa variedad de marcas que hacen un guiño al universo warholiano.

Pero, el Pop Art no solo está presente en el diseño publicitario de anuncios estáticos, sino que también se utiliza en medios audiovisuales, como es el caso de los spots de iPod + iTunes.

Existen hasta blogs de artistas que transmiten claves de cómo adentrarse gracias a una serie de pasos en el Pop, que pasan por colores vivos y brillantes, una tipografía de estética redondeada, la adecuada textura en los materiales empleados y el uso de logotipos chillones (Vizcaíno, 2019). Algunos recogen entre sus características la decontextualización del objeto cotidiano a modo Duchamp, al igual que crear imágenes incongruentes, provocadoras y con humor. La investigadora en artes y diseño Rebecca Gross, anuncia en su Web 10 maneras de aplicar el Arte Pop a tu diseño que enumera como consejos ${ }^{7}$.

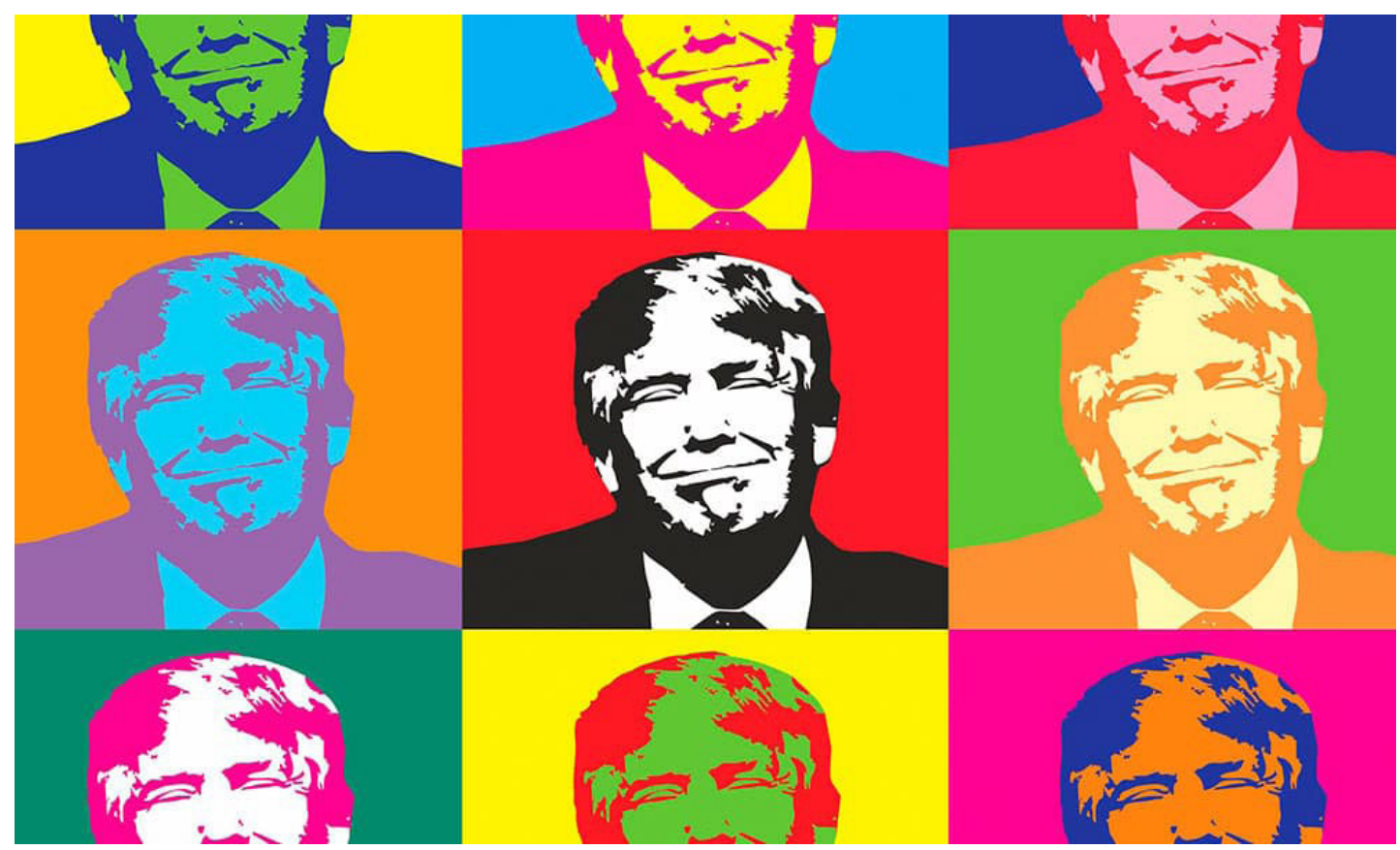

Figura 2: Póster del expresidente Trump ${ }^{8}$

En el mundo educativo son habituales los trabajos con estética Pop en los primeros años de escolarización, incluso en diseños más sofisticados en Escuelas Superiores de Diseño o Escuelas Técnicas. Este magnetismo viene dado porque parte del arte Pop está basado en el arte comercial (ilustraciones, etiquetas, diseño de envases, pósters, etc.) apropiándose de ello. Según Danto (1999: 107) ese apropiacionismo del Pop procede "de los diseños que ya habían pasado algún tipo de prueba estética (...) seleccionados porque se suponía que atrapaban al ojo".

Un ejemplo reciente en 2018 fue la celebración de la firma PILOT por sus 100 años de historia y dar la bienvenida a otros 100 años más, donde el artista internacional Mika se unió para crear una colección inspiradora, llena de energía, color y originalidad alrededor del concepto \#HappyWriting 9 .

\footnotetext{
7 Véase el blog de Rebecca Gross: https://bit.ly/3p140zQ. Enlace Web visitado el 19/01/2021.

8 Póster que ha sucumbido al guiño warholiano, inspirado en el "Díptico Marilyn" (1962), serigrafía de la Tate Modern de Londres, con la que unió Warhol 25 cuadros a color y otros tantos en blanco y negro, Recuperado de https://bit.ly/3tF8NKD. Web visitada el 11/12/2020.

9 (Canal Facebook: http://bit.ly/3q3QaOp. Enlace Web visitado el 19/01/2021)
} 
Ya que recurrimos al vídeo, si damos un paseo por la plataforma Youtube para visualizar vídeoclips de estética Pop, encontramos los que se situaban en ese momento de ebullición como The Beatles con Strawberry Fields forever ${ }^{10}$ y portadas como Sargents-Peppers. Después, los que continuaron como Queen con I want to break free $e^{11}$ que parodia a la serie británica de los 60 Coronation Street, hasta alcanzar el presente con Katy Perry con This is how we do $0^{12}$ o el vídeo de la china Jane Zhang titulado Dust my shouldesr off, tema de 2016.

Esa estética la situamos en la pequeña pantalla con series de Tv de la época como Batman; aquellas de ciencia ficción como Thunderbirds (Guardianes del espacio) cuyas súpermarionetas formaban una familia de rescatadores afrontando infinidad de peligros ${ }^{13}, \mathrm{y}$ la archiconocida Star Trek, con sus aventuras interestelares en la famosa nave Enterprise. Una estética y gusto de esos años 60 continuado en el siglo XXI con Mad Men y Pan Am.

En el mundo de las marcas existen retazos Pop indiscutibles como los famosos logos o imagotipos de Pepsi, Cocacola, la lengua de los Rolling Stones, cadenas de comida rápida, emisoras especializadas en público joven como los 40 Principales, el logo de Chupa Chups (realizado por Dalí sobre 1969), el de la mejor liga de baloncesto: NBA (por Alan Siegel en 1969), los equipos que la integran, la liga de fútbol americano: NFL, etc.

Un branding, cuyo trabajo de gestión de marca, planifica y posiciona a modo de estrategia una empresa, muchas de las cuales apuestan por este estilo Pop con la pretensión de que sea duradera a la hora de ser percibida.

De Pepsi, al igual que Coca-Cola, Warhol se inspiró y apropió, respetando sus colores y grafía, con esa inmediatez de reconocer lo "perteneciente a la cultura de masas y al uso, con el mismo tono optimista de un cartel publicitario" como en Close cover before striking (PepsiCola) (De Villena, 2006. 72). Warhol hizo de algo no creado por él, en obras icónicas, a modo de carteles publicitarios, logrando un prestigio que pudo saborear holgadamente en vida.

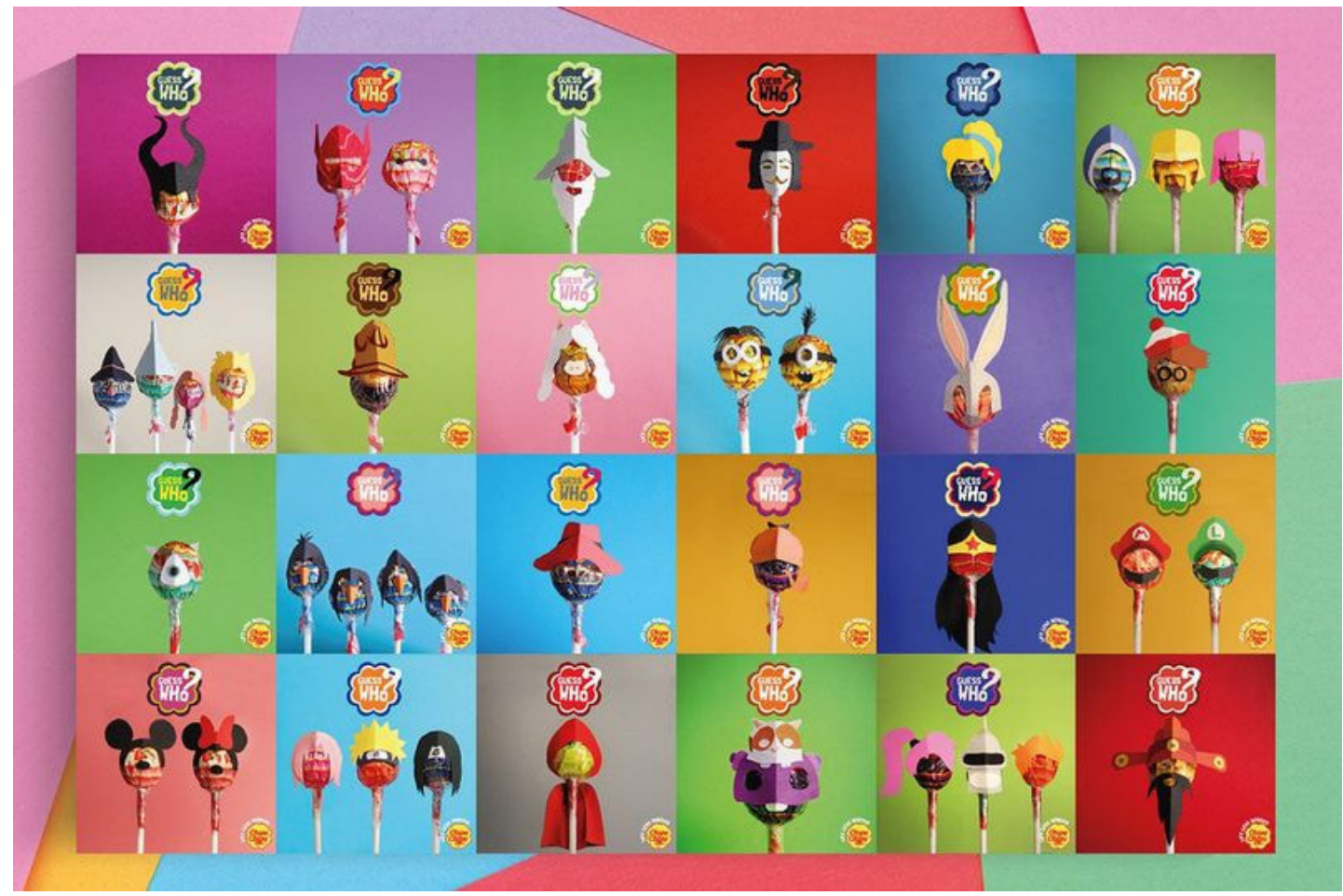

Figura 3. Campaña de chupa chups creada por el director creativo We Yi Boo en $2015^{14}$.

10 (Canal Youtube: https://bit.ly/36QBRoH. Enlace Web visitado el 19/11/2020).

11 (Canal Youtube: https://bit.ly/2YUADEz. Enlace web visitado el 21(01/2021).

12 (Canal Youtube: https://bit.ly/3q5ZFN6. Enlace Web visitado el 23/01/2021).

13 (Canal Youtube: https://bit.ly/3tF8iQL. Enlace Web visitado el 22/01/2021)

14 No sólo repite la imagen de la icónica paleta como en la serie de Marilyn, sino que también se inspira en personajes de la cultura popular, y cada Chupa Chup representa una caricatura diferente como Mickey y Minnie Mouse, Super Marios Bros, etc. Recuperada de http://bit.ly/3rzYc20. Web visitada el 016/12/2020. 
Las agencias publicitarias se han hecho eco de las icónicas imágenes, y el incremento de logos con influjos Pop no ha dejado de crecer, ya sean anuncios como las gafas Rayban, el canal de Televisión MTV, o en el campo del diseño arquitectónico o estructuras urbanas como el Instituto de sonido y visión de Hilversum (Holanda), establecimientos de comida rápida como la peruana Bembos, hasta el mobiliario e interiores como la silla Panton (1958) de Verner Panton, el célebre sillón bola (1962) o la silla Pastille (1967) del finlandés Eero Arnio, así como las sillas de Eero Saarinen, pionero del diseño orgánico, etc., colecciones consideradas en el diseño de mobiliario relevantes en el siglo XX.

La escultura Pop sobredimensionada se deja sentir por ejemplo en la silla Joe en forma de guante de béisbol en homenaje a Joe DiMaggio por parte del trío de Pas, D’ Urbino \& Lomazzi para Poltronova $(1970)^{15}$. No es extraño que el Pop se manifestara en diseños cotidianos, contrarios al buen diseño y la seriedad de los 50, con connotaciones infantiles, barato por dirigirse a un mercado joven y, a veces, de precaria calidad, con diseñadores como Peter Murdoch, Olive Sullivan, Martin Sharp, Piero Gatti, etc. (Fiell, 2000: 198, 569 y 622).

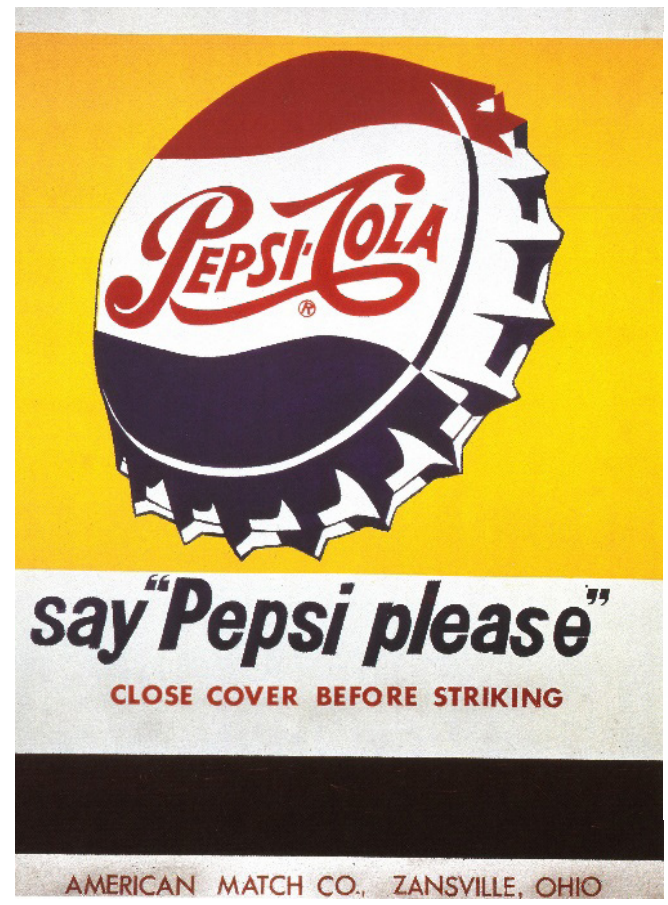

Figura 4. Logotipo PEPSI de los años $40^{16}$.

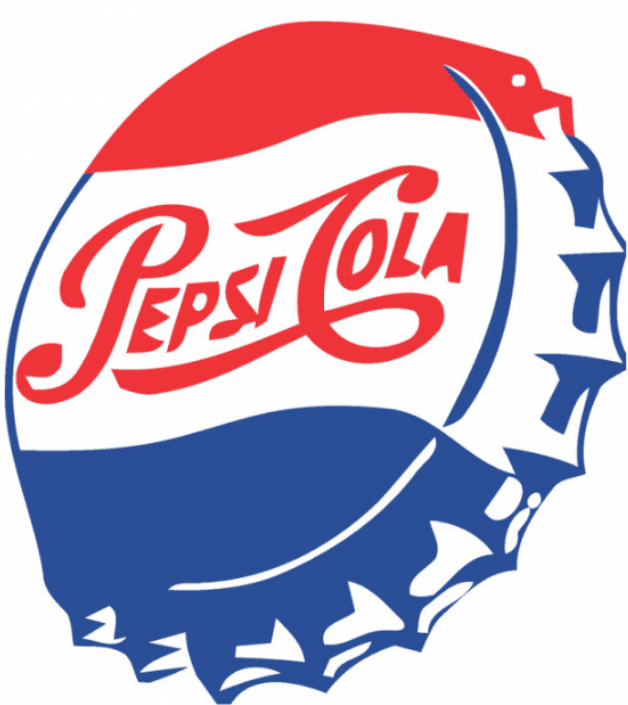

Figura 5. Warhol. Close cover before striking (pepsi-cola). Acrílico, pastel, letraset y papel abrasivo sobre lienzo. 1962 (Villena, 2006).

Un ejemplo actual son las galletas Tosta Rica y la promoción sobre un concurso de dibujo que recuerda a esos polípticos Pop ${ }^{17}$. En muchos de sus envases, como la versión de chocolate, aportan en su reverso múltiples paneles multicolores con diferentes niños mostrando dibujos.

Existe un Trabajo Fin de Grado de Fernández Santamaría (2016) donde se recogen numerosos ejemplos Pop en campañas publicitarias, desde la moda con las gafas Ray-Ban, vestidos de Versace, Pepe Jeans y los accesorios de la firma Coach, pasando por bebidas (cervezas como Indio, Sol, Stella Artois y el champagne Dom Perignon), hasta el sector automovilístico (Smart, Peugeot, Lexus, Citroën, etc.).

La cultura Pop del diseño no quedó estancada en los años gloriosos del Pop, como comprobamos en el arquitecto George Sowden y su vitrina D’ Antibes para Memphis (1981)

15 Véase la silla Joe en la Web: https://bit.ly/2Znkhby

16 Se le agregó el color azul a la mezcla, ya que solo era rojo. El rediseño persiguió dos objetivos: destacarse de Coca Cola y mostrar su apoyo a los Estados Unidos durante la Segunda Guerra Mundial por el tricolor de la bandera de los Estados Unidos). Recuperado de http://bit.ly/3jsEi6f. Web visitada el 07/01/2021.

17 (Canal Youtube: https://bit.ly/2OiTlnv. Enlace Web visitado el 09/01/2021). 
desde su estudio de diseño en Milán, al igual que hizo un componente de este grupo Memphis, Peter Shire, cuyos colores brillantes y tonos descarados ejemplifican el posmodernismo californiano con el sillón Bel Air (1982), o el aparador Cantaride de Alessandro Mendini y Bruno Gregori para Zabro-Zanotta (1984) (Fiell, 2000: 646).

Desde el punto de vista del mercado, el Pop continua al alza, con datos de 2012 donde situaban a Warhol como el pintor más vendido en subastas (Pulido, 2013). Colbert y Cuadrado (2015: 68), afirman que son cuatro los factores que influyen en el consumo individual de productos culturales complejos: los valores familiares que fomentan o rechazan las artes; el contexto educativo y el valor que éste concede a las artes; el hecho de haber asistido en la infancia a espectáculos teatrales y museos; y la práctica no profesional de actividades culturales.

Pensamos que a estas variables pueden abrirse otras debido al incipiente mercado asiático, como por ejemplo los nuevos ricos, que no saben por dónde empezar. Es tal su crecimiento que se manifiesta entre otras cosas en la aparición en 2012 de la casa de subastas China llamada Poly Auction con sede en Pekín, la cual se ha hecho un hueco entre las dos grandes firmas Sotheby's y Christie's, situada como la tercera casa de subastas más importante del circuito internacional. En palabras de Sanz (2018), China se ha convertido en una de las mejores plazas del arte contemporáneo, con ciudades referentes como Pekín, Shanghái o Hong Kong.

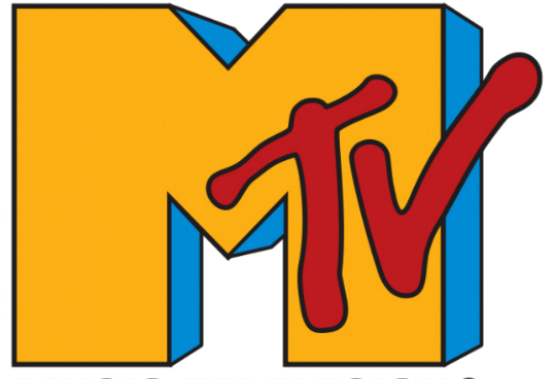

MUSIC TELEVISION ${ }^{\circledR}$

Figura 6. Logo del canal de televisión MTV.

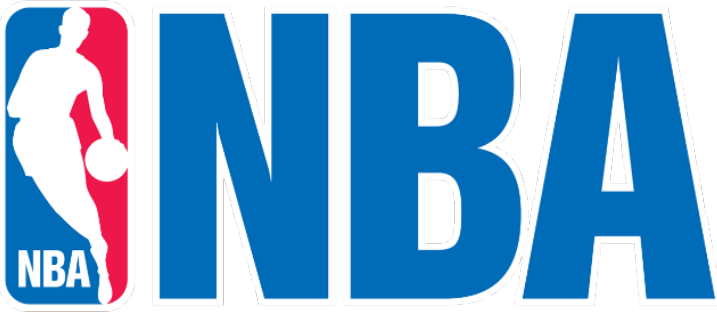

Figura 7. Logo de la liga de baloncesto norteamericana NBA ${ }^{18}$.

Vindel (2008: 230) recoge varios ejemplos y cita a los famosos cowboys de la marca Marlboro creados por Richard Price como estereotipo machista americano en publicidad buscando ese apropiacionismo tradicional de la cultura popular del vaquero de principios de los años 80, que el tiempo desacreditó, y que perdura en el imaginario.

Aplicado a la gráfica, decir que el Pop inspira a los publicistas no es nada nuevo, y la prueba es constante. En este caso campañas que son un remix de obras referentes del Pop como la citada de Ray Ban en 2009, en la que el contraste de colores recuerda a la pauta utilizada por Warhol en muchas de sus obras. También, existe la tendencia en videoclips de artistas como Lady Gaga o portadas de revistas como la que protagonizó en 2009 en el nº61 de $V$ Magazine fotografiada por Mario Testino, con ese uso de la extravagancia. Colores vivos y formas, que salpican intencionadamente el cine de Almodóvar, cuya estética se ha podido ver en toda su trayectoria, desde Pepi, Luci, Bom y otras chicas del montón (1980), pasando por Tacones lejanos (1991), Volver (2006), hasta Los amantes pasajeros (2013) (Chamberlain, Martínez y Romero, 2015). Un arte Pop que el mundo del cine lo demuestra con guiños de otros directores como Cita en las Vegas (1964) de George Sidney, American Grafitti (1973) de George Lucas, La naranja mecánica (1975) de Stanley Kubrick, Trainspotting (1996) de Danny Boyle, Amélie (2001) de Jean-Pierre Jeunet, y Del revés (2015) de Pete Docter y Ronnie del Carmen.

Por ejemplo, los créditos finales de muchas películas se han convertido en verdaderas obras de arte en diseño, como en Spiderman: Homecoming (2017), acompañado del tema de Los Ramones Blitzkrieg Popcon, con alusivos hacia el dólar de Warhol o el estilo de Lichtenstein ${ }^{19}$.

Raquejo (2013: 177), habla de esa influencia Pop en el paisaje, cuyos espacios comunes que habitamos (bares, iglesias, universidades, etc.) son escenarios que "preconfiguran un

18 Imágenes recuperadas de: http://bit.ly/3cQo7hB. Web visitada el 16/01/2021. https://bit.ly/36WJ1I6. Web visitada el 17/01/2021.

19 (Canal Youtube: https://bit.ly/3aMTS8Q. Enlace web visitado el 25/01/2021). 
rol que condiciona nuestro comportamiento", y es Richard Hamilton un impulsor de lo que predijo en la exposición This Is Tomorrow (1956), como estilo de vida doméstica, que "no ha hecho sino extenderse a todos los ámbitos de la cultura y de la vida" (Raquejo, 2013: 180), por lo que el mundo del consumo contamina y transforma nuestro entorno, algo que puede trasladarse a nuestros paisajes urbanos, en un mundo que produce paisajes para el consumo. Respecto a esto, diría Cossi (2000) que las formas culturales europeas se americanizan hace ya más de cincuenta años, debido en parte a esta cultura Pop.

Se necesita de gusto en estética para tener éxito en publicidad, y León (1995: 23) afirma que la publicidad escoge muchas veces estilos artísticos para alcanzar cotas de popularidad, ya sea cubismo, art nouveau o el arte pop. Para este autor, las propuestas de la publicidad son el placer, gusto estético y ensoñación, y sugiere mantener vivo el optimismo. Propuestas aplicadas con mejor o peor juicio, definen antropológicamente un modelo o perfil.

$\mathrm{El}$ arte pop fue una protesta en muchos aspectos sobre el mundo de consumo, y su matiz reivindicativo sigue vigente en artistas que convierten este estilo en denuncia, como hace la artista colombiana Beatriz González ${ }^{20}$, la cual trata en la serie de Las delicias o Mátame a mí que yo ya vivi (1996), ciertos acontecimientos políticos muy violentos en su país, como la marginación de la mujer y su dolor por esa posición. Todo expresado por colores que significan su activismo.

Aunque Urueña (2019: 43) postula que los padres del Pop querían ensalzar la cultura popular y la producción industrial, posiblemente Warhol se identificaría más en esa protesta de Beatriz González de lo que podemos imaginar. Porque el Pop surge según palabras de Bourlot (2010: 94) como:

Una crítica a esa nueva sociedad, la sociedad de masas, la sociedad consumista. Es por eso que el movimiento basa sus temas pictóricos en la vida cotidiana, intentando reflejar las realidades de una época, su estado de ánimo, sus cambios en la conducta, mostrando el cambio cultural producido. Los temas, las formas y los medios del arte Pop no son más que el reflejo de los rasgos esenciales de los años sesenta.

Y, aun teniendo mucho de ironía, el Pop fue cercano al pueblo por reflejar su cotidianidad y vida de consumo, que continua en muchos artistas por la conexión de las siempre actualizadas tecnologías y los medios de comunicación, que marcan el devenir del Pop en sus inicios.

\section{CONCLUSIONES}

En consonancia con el concepto de "aldea global", Warhol sugirió supuestamente sobre 1968 que todos tendríamos en el futuro quince minutos de fama, en una visión muy acertada en la sociedad capitalista.

Este consumo bulímico de imágenes como afirma Vettese (2013: 80 y 131), apropiándose de la imagen masificada de los años 60, está más arraigado actualmente, ya que la era digital permite ser nosotros mismos productores y realizadores de vídeos, o fotógrafos en las redes sociales. Narraciones visuales que dejan atrás a aquellas de otros siglos en los que el arte era el medio de comunicación más potente en sociedades analfabetas, porque, como ya decía Warhol, todo es cuestión de marketing.

Ante la globalización: diferenciación, decía Nacach (2004: 31 y 32), cuyos discursos publicitarios proponen métodos personalizados para curar todo tipo de dolencias o indisposiciones sociales, con actos de consumo que generan en las personas un valor fijo de identidad con el mundo, una falsedad de vida en modo virtual, que se incrementa en un periodo de pandemia (como la Covid-19) e indefensión.

En marketing cultural, el uso de una marca (ya sea un nombre o símbolo) y su estrategia, suele evocarnos mentalmente a ella. Ya sea el teatro de la Scala en Milán, el Guggenheim o el MOMA en N. York, extienden sus marcas en el mercado (Colbert y Cuadrado, 2015: 47). Warhol tenía clara esa visión y obtuvo ese prestigio en su creación perdurable, porque esa expresión del ciclo de vida del producto es infinita en él, una variable que aún es más potente desde su fallecimiento, elevándolo a cotas de mito y chamán de las artes.

20 (Canal Web de Beatriz González: http://bit.ly/3qexUSN. Enlace web visitado el 18/01/2021). 
Vettese (2013: 101) recoge sobre el sistema del arte o el mercado que bien conocía Warhol, que "el éxito inicial pasa a través de mallas que tienen que ver con la determinación del autor, su suerte en los encuentros, la oportunidad y un sistema de toscas reglas, pero tan delicadas que han de manejarse con cuidado".

Warholdesdeun prisma publicitariousabaunatécnicainformaldecreatividad, buscando ideas novedosas, sorpresivas como diría García-Uceda (2011: 292), que en terminología de creatividad podemos llamar sinéctica, donde vincula elementos aparentemente inconexos, distintos, cuya unión o conjugación de ideas pueda surgir algo original o distinto. Reiterativo con los objetos, "vacía las obras frente a la publicidad que las llena” (De Diego, 1999: 173).

No pasó de estrella a héroe porque su muerte fue anónima, discreta, sin el destino de James Dean o Jackson Pollock, porque como él mismo decía, tuvo la oportunidad con los disparos fallidos de Valerie Solanas el 3 de junio de 1968 en The Factory: "Si hubiera muerto ese día hoy sería una figura de culto" (De Diego, 1999: 27).

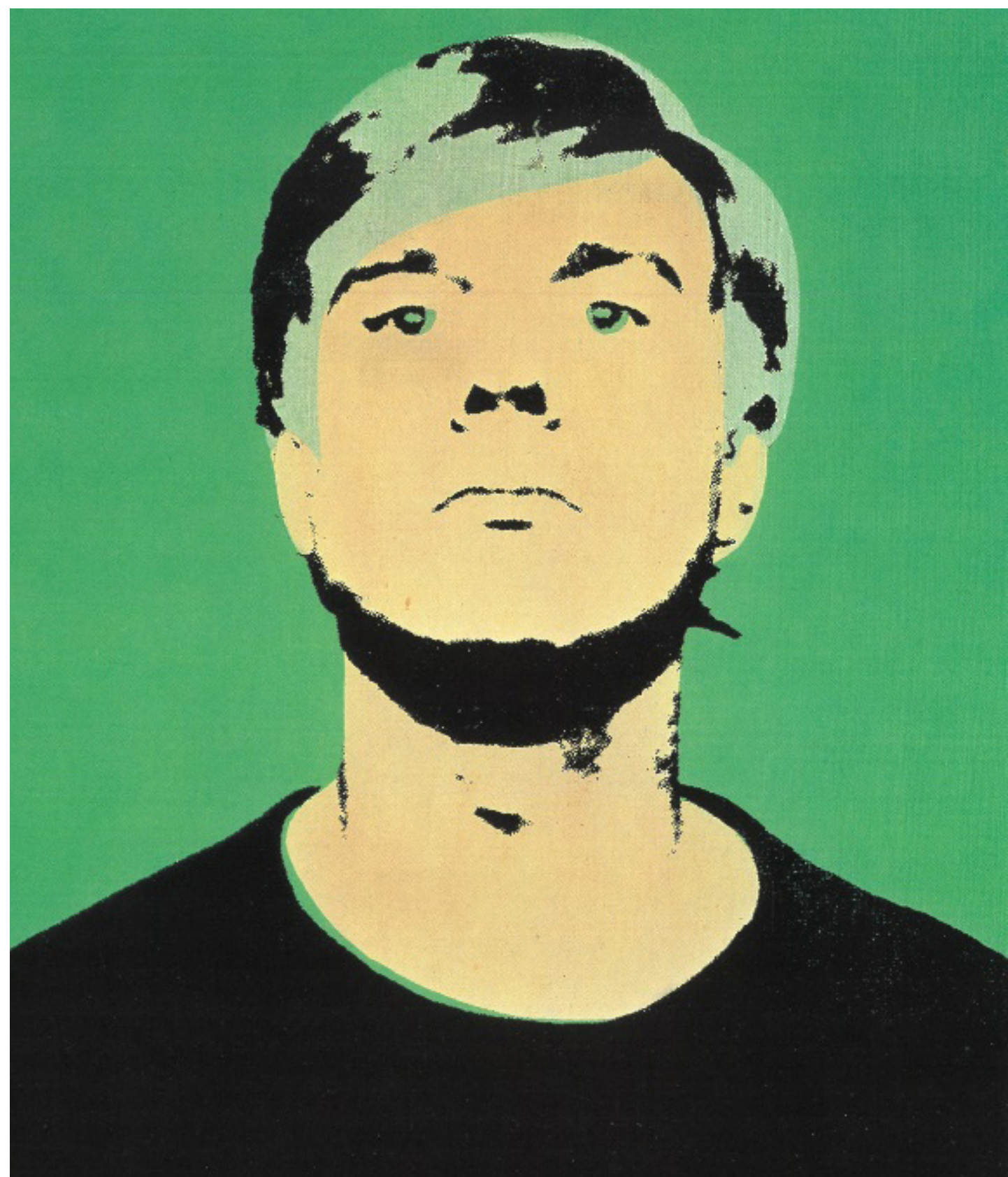

Figura 8. Warhol. Self-portrait (1964). Serigrafía, polímeros sintéticos y acrílico sobre lienzo. (De villena, 2006)21.

21 Ubicada en The Andy Warhol Foundation, N. York. Se muestra desafiante, a modo de proscrito y criminal, en referencia a la obra de Duchamp Wanted \$ 2000 Reward de 1923, en esa máscara de seguridad en la que se refugiaba. 
Warhol tuvo un antes y un después desde que acudió a N. York, al igual que con ese intento de asesinato, momentos claves en su devenir. Buscó historias y belleza que no tuvo en su juventud, obsesionado por su nariz ancha, su falta de glamour alejado de las fantasías de las revistas, por lo que evitó esa parte de su vida. Se reinventó en lo que él quería y se convirtió para muchos en ese sueño americano que uno puede conseguir, como define De Diego (1999: 128), encarnado como nadie en el "mito americano", todo de la nada. Contrapuestos con su pasado y entre la esfera privada y pública: pobre/rico, feo/guapo, inmigrante/glamour, anonimato/celebridad, conservador/homosexual, productor/consumidor-coleccionista, timidez/fama, Pittsburgh/ N. York, etc.

Warhol se convirtió en su propio producto autodestructivo, obsesionado con poseer, símbolo de consumo total, ya que fue un acumulador, como dice De Diego (1999: 146) "comprar es más americano que pensar". Huyó siempre de la vulgaridad, de la mundanidad, pero acabó en ella como celebridad del populismo plebeyo, acechándole una melancolía o nostalgia conforme poseía y se enriquecía más, entre una riqueza de soledad (buscando relación con artistas más jóvenes porque podían ser amigos y comprendían mejor su obra), y con un final en 1987 que nunca hubiera deseado, lejos de destinos trágicos célebres, en un hospital para someterse a una operación rutinaria de vesícula de forma anónima y nada heróica.

Mientras ponemos fin a este artículo, los encargos de interiorismo con acento Pop continúan en diseñadores, agencias o estudios como las españolas Tuo Agency o Muher, así como ejemplos internacionales como la diseñadora Jannat Vasi ${ }^{22}$ o el Estudio de Letizia Yagüez $^{23}$. Encargos para clientes que quieren color, optimismo, un remake de aquel pasado en iconos como Audrey Hepburn, Elvis o Madonna, ilimitado en decoración, que buscan espacios alegres, vibrantes, atractivos, chillones y jóvenes. La alta costura, por ejemplo, "retrocede siempre veinte años reciclando el gusto por lo anterior, haciendo nuevo lo que ya era viejo perdido" (Nacach, 2004: 59).

Fenómeno Kitsch que perdura, cuyos contrastes los hemos visto en televisión con la casa de Alaska. Por ejemplo, la Escuela Madrileña de Decoración se declara fan del Kitsch mostrando los proyectos de sus alumnos, y aquellos espacios de exposición en las ediciones de la Casa Decor en Madrid²4.

Finalizamos apuntando esa continuidad con artistas como la joven cantante Billie Eilish, activista y alejada de cualquier estereotipo, o la artista japonesa Yayoi Kusama, marginada durante muchos años, pero que mantuvo firmes sus ideales, desplegando su trabajo performativo en lo que se ha llamado un "look Kusama" (Espinosa, 2014). Una moda Pop que es fuente de inspiración en colecciones de todo el mundo, firmas o diseñadores como Phillip Lim, Pepe Jeans, Jean-Charles de Castelbajac, Prada, Versace, etc., con lo cual, el Pop sigue muy vigente en la actualidad ya sea en publicidad, cine, moda, merchandising o música.

Toda una herencia de Warhol, que cuando ambicionaba un reconocimiento por galerías de arte neoyorkinas con las que sufrió ciertas frustraciones en esos comienzos de 1960, posiblemente no se imaginaba que su estética trascendería a nivel planetario, signo inconfundible de un legado atractivo de lo popular y el consumo, aún si cabe más asombroso en el siglo XXI, el cual es más desmedido y potente en cultura de masas.

\footnotetext{
2 (Canal web de interiorismo: https://bit.ly/2N7Zfr2. Enlace Web visitado el 21/01/2021)

(Canal Web de interiorismo: https://bit.ly/3q0hsoQ. Enlace Web visitado el 21/01/2021)

(Canal Web sobre la exposición de la Casa Decor de 2020: http://bit.ly/3a0lw2T. Enlace Web visitado el 26/01/2021).
} 


\section{BIBLIOGRAFÍA}

- Amezcua Díaz, I. (2013). El pop art inglés y su influencia en el diseño interior y la arquitectura. Revista Arte y Diseño, Vol. 11 ( $N^{o}$ 2). Universidad Autónoma del Caribe, 15-22

- Botías, A. (2017, 31 de enero). Los que nacemos junto al mar siempre lo tenemos dentro y lo añoramos. La Verdad. http://bit.ly/3qewFmB (Web visitada el 25/01/2021)

- Bourlot, C. (2010). Pop Art: ¿el movimiento artístico de mayor cercanía con el pueblo? Creación y Producción en Diseño y Comunicación [Trabajos de estudiantes y egresados], $\mathrm{N}^{\circ}$ 35. Universidad de Palermo. Fabiola Knop, 93-97.

- Chamberlain, M. Raquel Martínez, R. y Cristina Romero, C. (2015), Arte Pop en Publicidad, (Trabajo Final de Grado). Universidad de Sevilla.

- Colbert, F. y Cuadrado, M. (2015). Marketing de las artes y la cultura. Barcelona: Ariel.

- Cosano, A. (2019, 21 de enero). Pilot by Mika. Años de eterna juventud. Relojes y estilo de vida. Recuperado de http://bit.ly/3tGpdTl. (Web visitada el 21/01/2021).

- Cossi, G. (2000). Estrategico de marketing e americanizzacione dell'occidente: Il caso della Pop-Art. Studi di Sociologia, Vol. 38, nº 1, Vita e Pensiero, Università Cattolica del Sacro Cuore, 35-52.

- Danto, A. C. (2011). La transfiguración del lugar común. Una filosofía del arte. Madrid: Paidós.

- Danto. A. C. (1999). Después del fin del arte. Madrid: Paidós.

- De Diego, E. (1999). Tristísimo Warhol. Cadillacs, piscinas y otros síndromes modernos. Madrid: Siruela.

- De Villena, L. A. (2006). Warhol, un mito ambiguo del arte moderno. Warhol (N $\left.{ }^{\circ} 5\right)$, Biblioteca El Mundo.

- Díaz Guitiérrez, Daniel (2010). Arte-publicidad, un binomio posible. Revista Internacional de investigación, innovación y Desarrollo en Diseño, Vol. 3. Universidad de Málaga, 1-11.

- Espinosa, G. (2014, 27 de julio). La estética Yayoi Kusama, El País. Recuperado de http://bit. ly/3p9y9x7. (Web visitada el 20/01/2021).

- Fanés, F. (2000). Pop Art y Minimalismo. Descubrir las Vanguardias. Madrid: Arlanza Ediciones.

- Fernández, Alicia (1999, octubre). Andy Warhol. Nº9. Bilbao: Suplemento cultural Pérgola.

- Fernández Campón, Miguel (2006). Andy Warhol, ser de transparencias, espacio holográfico y utopía realizada. Revista Norba-Arte. Vol. XXVI. Universidad de Extremadura, 225-242.

- Fernández Santamaría, Carolina (2016). Andy Warhol. La estética warholiana al servicio de la publicidad. (Trabajo Fin de Grado) Universidad de Valladolid.

- Fiell, C. y P. (2000). Diseño del siglo XX. Taschen.

- Gablik, S. (1984). ¿Ha muerto el arte moderno?. Madrid: Hermann Blume.

- García-Uceda, M. (2011). Las claves de la publicidad. Madrid: ESIC.

- Gompertz, W. (2018). ¿Qué estás mirando?. 150 años de arte moderno en un abrir y cerrar de ojos. Barcelona: Taurus.

- Guasch, A. M. (2000). El arte último del siglo XX. Del posminimalismo a lo multicultural. Madrid: Alianza Forma.

- Heredero Díaz, Olga y Chaves Martín, Miguel Ángel (2016). El arte en la publicidad. Tipologías del uso del arte visual en la comunicación comercial. Comunicación y Medios. $\mathrm{N}^{\mathrm{o}}$ 34. Universidad de Chile, 96-113.

- Honnef, Klaus (2005). Andy Warhol (1928-1987). El arte como negocio. Colonia: Taschen.

- Junca, H. (2010). Jasper, Bob y Andy. Revista Arcadia, Recuperado de http://bit.ly/3jwg0Z1. (Web visitada el 05/12/2020).

- León, J. L. (1995). Los efectos estéticos de la publicidad. Questiones publicitarias, $\mathrm{N}^{\circ} 4$, Universitat Autònoma de Barcelona (UAB), 9-26.

- Lucie-Smith, E. (1998). Movimientos artísticos desde 1945. Barcelona: Destino.

- Melero Guirado, Ramón (2019). Andy Warhol [Ausencias]. Revista de Humanidades, Arte y Cultura Independiente Eviterna, $\mathrm{N}^{\circ}$. Universidad de Málaga, 74-85.

- Nacach. P. (2004). Las palabras sin las cosas. El poder de la publicidad. Madrid: Lengua de trapo.

- Pinilla Hurtado, S. (2012). El arte Pop, amor y libertad. Institución Salazar y Herrera. $N^{\circ} 19$. 
Tiempo, 53-61.

- Pulido, N. (2013, 11 de enero). Warhol imparable, se alza como el artista más vendido en subasta en 2012. ABC. Recuperado de http://bit.ly/3a0IHKl. (Web visitada el 21/01/2021)

- Raquejo Grado, T. (2013). Herencias del paisaje Pop. Marketing y visión del territorio en el arte actual. Madrid: Revista Goya (343), Fundación Lázaro Galdiano, 166-181.

- Rodríguez Pedret, Carmen (1991). Miradas “Pop” en la ciudad contemporánea. Anales de Arquitectura. $\mathrm{N}^{\circ} 5$. Universidad Politécnica de Cataluña.

- Spies, Werner (1990). Andy warhol. Coches. Catálogo de exposición. (05 de octubre de 1990 al 5 de enero de 1991). Madrid: Fundación Juan March ${ }^{25}$.

- Pastor, C. (2016, 15 de febrero). El Nueva York de Warhol. El Mundo. Recuperado de http:// bit.ly/3jrUxAu .(Web visitada el 03/01/2021)

- Petit, Q (2019, 19 de julio), Retratos de la relación turbulenta entre Warhol y Basquiat, El País Semanal. Recuperado de http://bit.ly/3aJRm33. (Web visitada el 12/12/2020).

- Sanz Guillén, A. (2018, 23 de marzo). El mercado artístico de China (III). Galerías y casas de subastas. Revista Cultural Ecos de Asia. Recuperado de http://bit.ly/2OleoWv (Web visitada el 27/01/2021)

- Urueña López, J. E. (2019). Beatríz González: entre el Arte Pop y la “indexicalidad” del fenómeno de la violencia. Inmaterial. Diseño, Arte y Sociedad, 4(7), 15-43.

- Vettese, A. (2013). El arte contemporáneo. Entre el negocio y el lenguaje. Madrid: Rialp.

- Vindel Gamonal, J. (2008). Arte y publicidad: Del arte Pop a la Crítica institucional. De arte, Revista de Historia del Arte, $\mathrm{N}^{\circ} 7$, Universidad de León, 213-234.

- Vizcaíno, C. (2019). Pop Art, características, obras y claves para entender el arte pop, Candela Vizcaino. Recuperado de http://bit.ly/39YzzWE. (Web visitada el 09/01/2021).

25 Esta exposición la comenzó Warhol en 1986 por encargo de Daimler-Benz dedicada a los automóviles con motivo del centenario de su historia y que no pudo concluir por el fallecimiento del artista. 